\title{
PROSES PENANGANAN TIANG LISTRIK AMBLAS Studi Kasus: Kelurahan Ratu Sima - Dumai Barat
}

\author{
Adelia Alfama Zamista ${ }^{1 *}$ Muhammad Musri ${ }^{1}$ \\ ${ }^{1}$ Program Studi TeknikIndustri, Sekolah Tinggi Teknologi Dumai \\ Jln.Utama Karya Bukit Batrem II-Dumai -Riau \\ *Email: alfadelia17@gmail.com
}

\begin{abstract}
Abstrak
Studi ini secara khusus mencoba untuk memaparkan proses penanganan tiang listrik amblas. Diketahui bahwa tiang listrik merupakan salah satu komponen penting dalam proses transmisi listrik dari gardu-gardu PLN ke masyarakat sebagai konsumen. Namun untuk beberapa daerah dengan kondisi tanah yang tidak mendukung, kelurahan Ratu Sima - Dumai Barat misalnya dengan komposisi tanah didominasi oleh gambut (dan/atau rawa gambut) yang memiliki karakteristik mudah amblas dan kemampuan menahan tekanan yang rendah menyebabkan beberapa tiang listrik yang dipasang di daerah ini mudah amblas. Berdasarkan hasil survei lapangan dan pemetaan per bulan April 2019 menunjukkan 11 tiang listrik amblas di daerah studi kasus. Kondisi ini bila tidak segera ditangani akan menyebabkan proses transmisi listrik tidak berjalan dengan baik atau bahkan terhenti. Oleh karena itu perlu dilakukan perbaikan atau penambahan komponen pada tiang listrik yang telah terpasang agar tidak semakin amblas atau bahkan tumbang. Berdasarkan hasil penelitian diketahui bahwa proses penanganan tiang listrik yang amblas dapat dilakkan dengan pemasangan manshet khusus pada tiang listrik. Ketebalan manshet kuhususyang dipasang pada tiang listrik yang amblas berbeda-beda tergantung dari kondisi tiang listrik saat dipasangi manshet dan kondisi tanah tempat tiang listrik berdiri.
\end{abstract}

Keywords:Tiang listrik amblas, survei lapangan, manshet khusus.

\section{PENDAHULUAN}

Perusahaan Listrik Negara (PLN) atau nama resminya adalah PT PLN) adalah sebuah badan usaha milik negara (BUMN)yang mengurusi semua aspek ketenagalistrikan yang ada di Indonesia.Unit PT PLN dibagi dalam beberapa Wilayah untuk mengurusi pembangkitan, penyaluran (transmisi),pengaturan beban, dan distribusi kepada pelanggan (PLN, 2019; Wandaliya, C, 2017).Untuk wilayah Kota Dumai - Riau kantor ini melayani kebutuhan terkait listrik masyarakat. Layanan seperti pengajuan pemasangan listrik, pengajuan naik tegangan, cek tagihan listrik, pembayaran listrik hingga komplain.
Pelaksanaan fungsi transmisi listrik oleh PT PLN memerlukan beberapa komponen penting, salah satunya adalah tiang listrik. Tiang listrik merupakan komponen dari saluran udara tegangan rendah atau saluran udara tegangan menengah yang mempunyai fungsi utama menyangga konduktor listrik (Winayu, 2010). Ada beberapa jenis tiang listrik yang biasa digunakan oleh PT PLN, yaitu:

1. Tiang Beton

Tiang beton merupakan tiang pratekan berpenampang bulat konis berongga di tenggahnya yang pembuatannya mengunakan mesin putar. Tiang jenis ini yang banyak di pakai 
PT PLN karena harga nya yang lebih murah dari tiang besi.

\section{Tiang Kayu}

Pada beberapa wilayah pengusahaan PT PLN bila suplai kayu memungkinkankayu dapat digunakan sebagai tiang penopang penghantar listrik.

3. Tiang Besi

Jenis tiang yang terbuat dari pipa besi yang disambungkan hingga diperoleh kekuatan beban tertentu sesuai kebutuhan. Walaupun lebih mahal pilihan tiang besi untuk area/wilayah tertentu masih diizinkan karena bobotnya lebih ringan dibandingkan dengan tiang beton jika di wilayah tersebut belum ada pabrik tiang beton.

Selama penggunaan tiang listrikdihadapkan pada beberapa kemungkinan kendala dan kerusakan salah satunya adalah amblasnya tiang akibat kondisi tanah yang tidak stabil.

Studi kasus pada penelitian ini dilakukan di kelurahan Ratu Sima - Dumai Barat. Secara geologi Kecamatan Dumai Barat disusun oleh batuan sedimen berumur muda (Kuarter) berupa alluvium (Qp) dengan bahan penyusun lempung, pasir, kerikil, sisa tumbuhan (gambut), dan rawa gambut, sedangkan pada daerah perbukitannya disusun oleh batuan sedimen berumur tua (Tersier) dengan bahan penyusun batu lumpur kelabu berkarbon terbioturbasikan, batu pasir halus, umumnya kehalusan rendah sampai sangat rendah (Astuti, 2016).

Secara umum daerah Dumai Barat dikenal dengan daerah yang tersusun atas gambut dan rawa gambut, yang mana menurut Noor, Masganti dan Agus (2014) salah satu karakteristik tanah gambut adalah mudah ambles dan daya dukung lahan terhadap tekanan rendah. 2 karakteristik inilah yang menjadi penyebab tiang listrik di daerah Dumai Barat rentan amblas. Diketahui per bulan April 2019 ada 11 tiang listrik amblas di kelurahan Ratu Sima - Dumai Barat.

Masalah tiang listrik yang amblas ini bila tidak segera ditangani akan menjadi masalah yang lebih besar, khususnya yang berkaitan dengan transmisi listrik. Oleh karena itu pada penelitian ini akan membahas bagaimana proses penangganan tiang listrik, studi kasus di kelurahan Ratu Sima - Dumai Barat.

\section{METODOLOGIPENELITIAN}

Mengacu pada tujuan penelitian, maka pendekatan yang dilakukan dalam penelitian ini adalah:

1. Melakukan studi pendahuluan ke PT PLN mengenai permasalahan yang berkaitan dengan transmisi listrik.

2. Melakukan tinjauan pustaka untuk pengumpulan studi literatur yang berhubungan dengan tiang listrik yang digunakan untuk transmisi listrik dan kondisi tanah yang berhubungan yang mempengaruhi kondisi tiang listrik. Serta literatur yang berkaiatan dengan penanganan tanah amblas khususnya penanganan tiang listrik amblas karena jenis tanah tertentu.

3. Melakukan survei lapangan untuk mendapatkan data keadaan tiang lisrik pada daerah studi kasus, menentukan jumlah tiang listrik yang amblas, seberapa jauh penurunan dan gambaran kemungkinan solusi untuk mengatasi masalah tiang listrik amblas.

4. Penyusunan rencana pemeliharaan tiang listrik yang amblas berdasarkan hasil survei lapangan dan studi literatur.

Bagan alir dari pnelitian ini diperlihatkan pada Gambar 1.

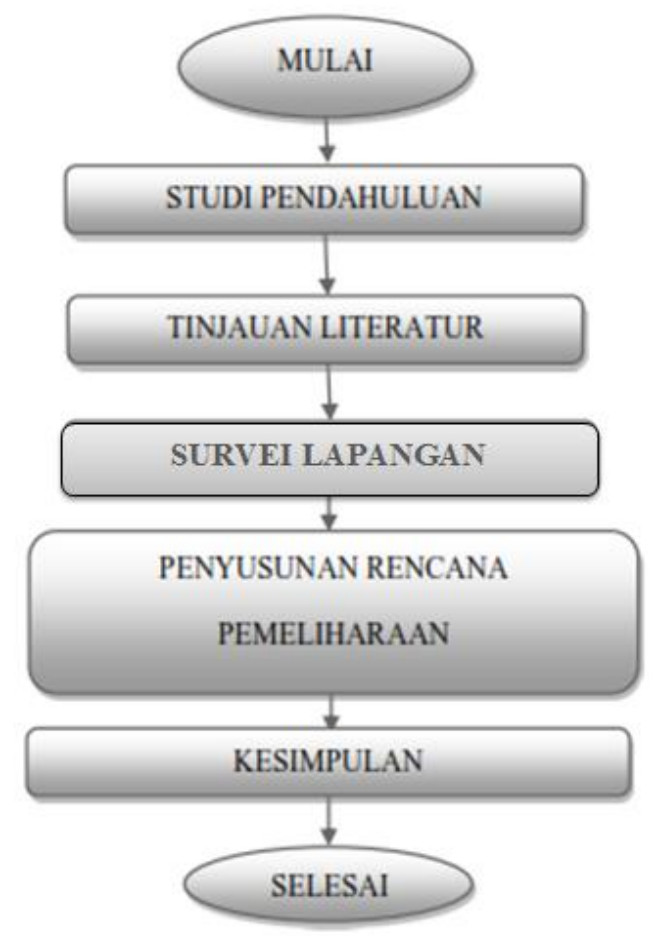

Gambar 1. Bagan Alir Penelitian 
2.1. Survei

Metode survei adalah penyelidikan yang diadakan untuk memperolehfakta-fakta dari gejalagejala yang ada dan mencari keterangan-keterangan secarafaktual, baik tentang institusi sosial, ekonomi, ataupolitik dari suatu kelompok ataupun suatu daerah. Metodesurveymembedah dan menguliti serta mengenal masalah-masalah sertamendapatkan pembenaran terhadap keadaan dan praktek-praktek yangsedang berlangsung (Nazir, 2003). Pada penelitian ini survei yang dilakukan adalah survei lapangan. Survei lapangan atau survei lokasi adalah tahapan awal yang sangat penting dalam merencanakan suatu kegiatan perencanaan proyek atau suatu bangunan, atau khususnya dalam penelitian ini untuk perencanaan penanganan tiang listrik amblas.

\section{HASIL DAN PEMBAHASAN}

Proses penanganan tiang listrik amblas meliputi beberapa tahapan.

\subsection{Survei}

Langkah awal dalam mengatasi tiang listrik yang amblas adalah survei. Survei dimaksudkan untuk mengetahui kondisi tiang listrik, kedalaman amblas, dan penyebab tiang listrik amblas.

Survei dilakukan oleh tim bagian teknik.Tim bagian teknik akan mendatangi lokasi tiang listrik yang sudah di tanam atau sudah di gunakan sebagai penyangga saluran udara tegangan rendah (SUTR) atau saluran udara tegangan menengah (SUTM), tim akan melihat tanda yang sudah dibuat sebelum nya di sekeliling tiang, guna tanda tersebut untuk melihat seberapa jauh tiang yang amblas.

Survei dilakukan beberapa kali untuk memastikan seberapa dalam tiang nya turun, jangka waktu nya tidak menentu dari seminggu sekali sampai sebulan sekali, bila amblas nya tiang sudah jelas atau bahkan sudah mencapai 1 meter maka akan di buat pemetaan laporan hasil survei.

\subsection{Pemetaan}

Pemetaan merupakan penggambaran parameter lapangan dan pola keruangan obyek dengan mempergunakan konsep kartografi, pada kertas dasar dalam sekala tertentu. Biasa nya pemetaan ini dibuat oleh tim survei.
Setelah survei kelapangan dan mendapatkan hasil bahwa memang terjadi nya amblas pada tiang listrik, maka tahap selanjutnya ialah pemetaan, dengan menggambar pola-pola tampak atas. Gunanya sebagai penanda tiang-tiang mana saja yang amblas, agar mempermudah tim antek untuk bisa melihat tiang mana saja yang amblas, yang kemudian bisa di beri manshet khusus

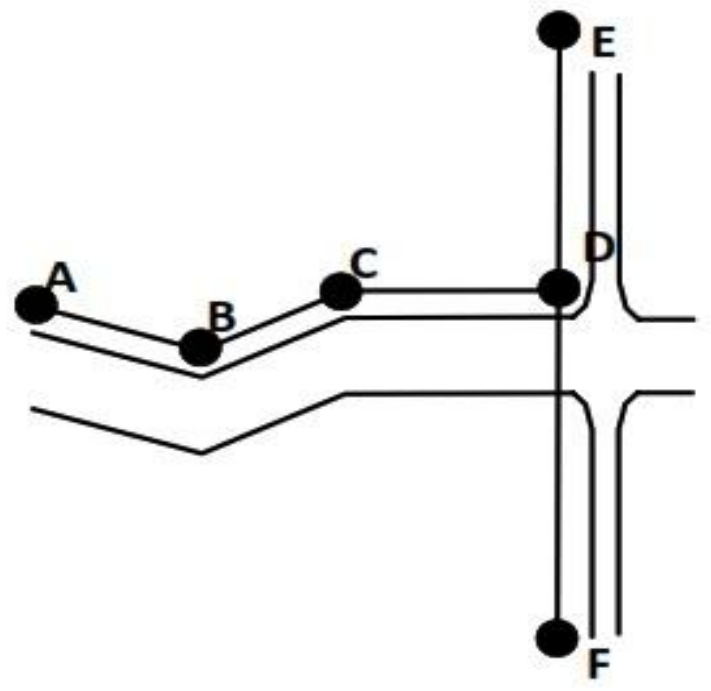

Gambar 2. Pemetaan Tiang Listrik yang Amblas

Gambar 2 memperlihatkan pemetaan tampak atas tiang-tiang listrik yang amblas yang berada di jalan meranti darat kota dumai, tiang yang di beri huruf abjad adalah tiang-tiang yang amblas,ada enam tiang yang mengalami amblas, apabila amblas nya tiang sudah melewati 1 meter maka akan di pasang manshet khusus.

\subsection{Pembuatan Manshet Khusus}

Pemberian manshet khusus ini dilakukan oleh tim antek yang akan di awasi oleh senior antek dan juga tim teknik. Untuk pemberian manshet khusus, petama-tama harus menyiapkan kerangka besi angker yang akan di cor bersama beton, guna untuk memperkuat kekutan manshet.

Setelah mempersiapkan besi angker tahap selanjutnya ialah menggali tanah yang berada di sekeliling tiang. Untuk pengalian nya, tanah harus digali persegi empat, karena manshet khusus ini berbentuk persegi empat. untuk kedalaman nya, sekitar sepertiga dari manshet khusus tersebut, karena bagian yang lainnya akan di biarkan menonjol keluar. 
Berikutnya ialah pemberian mal/cetakan, mal berbentuk persegi empat yang terbuat dari besi, guna untuk membentuk manshetkhusus menjadi persegi empat. Setelah mal di pasang dan besi angker di masukkan, maka cor-coran semen di masukkan ke dalam mal. Setelah kering mal akan di buka kembali untuk di gunakan pada tiang yang lain.Untuk melakukan semua pekerjaan tersebut senior antek telah membagi-bagi tim antek dalam berapa tim kecil. Guna untuk mempercepat pekerjaan dan meminimalisir waktu pengerjaan.

Berikut adalah gambar flowchart proses pemasangan manshet khusus yang dilakukan oleh tim antek.

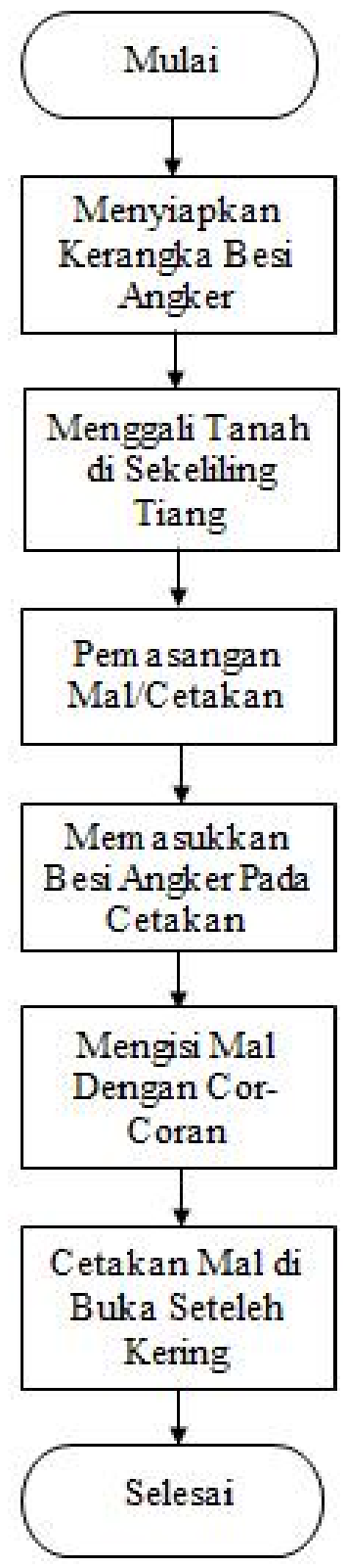

Gambar 3. Flowchart Pembuatan dan Pemasangan Manshet Khusus
Setelah dipasang manshet khusus yang dipasang untuk menahan tiang listrik yang amblas diperlihatkan pada Gambar 4.

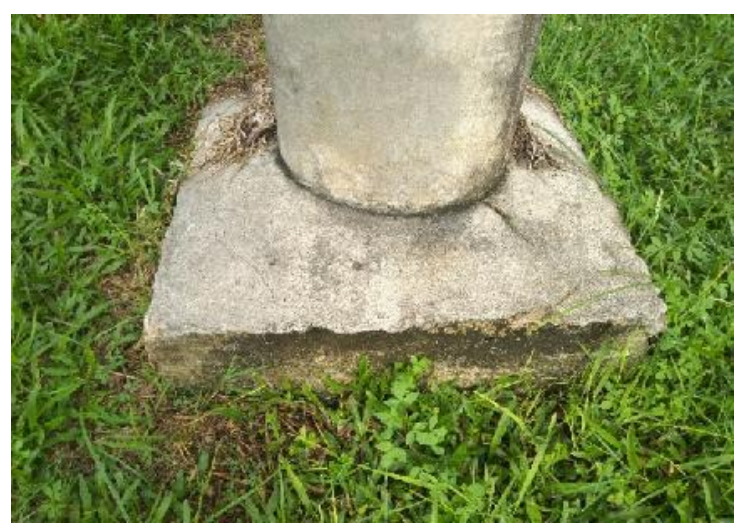

Gambar 4. Manshet Khusus

Ketebalan manshet khusus yang dipasang pada tiang listrik yang amblas dapat berbeda-beda. Tergantung dari kerusakan, kemirikan, dan kondisi tanah ditempat tiang listrik berada. Gambar 4 menunjukkan ketebalan rata-rata untuk manshet khusus yang dipsang di daerah studi kasus yaitu di Jalan Meranti Darat, Kelurahan Ratu Sima, Kecamatan Dumai Barat, Kota Dumai.

\section{Kesimpulan}

Proses penanganan tiang listrik yang amblas terbagi menjadi beberapa tahap, yaitu survei kelapangan, pemetaan posisi tiang yang amblas, pengarahan terhadap tim antek, dan yang terakhir pemberian manshet khusus. Pemasangan manshet khusus tersebut di lakukan oleh tim antek yang di awasi oleh senior antek dan tim teknik, dan pemasangan manshet khusus tersebut memakan waktu lebih kurang 30 menit.

\section{DAFTAR PUSTAKA}

Astuti, P. 2016. Studi Pengembangan Kawasan Perkotaan di Kecamatan Dumai Barat, Kota Dumai. Jurnal Saintis, Vol/ 16. No. 1. Hal 34-45, ISSN: 1410-7783. 
Nazir, M. 2003. Metode Penelitian. Jakarta: Salemba Empat.

Noor, M,. Masganti, Agus, F. 2014. Pembentukandan Karakteristik Gambut Tropika Indonesia. Balai Penelitian Pertanian Lahan Rawa. https://www.pantaugambut.id/uploads/de fault/resources/document/Bab_1Pembentukan_dan_Karakteristik1.pdf

PLN. 2019. Tentang Kami PT PLN, online dihttp://www.pln.co.id/, diakses pada tanggal 16 juni 2019
Wandaliya, C. 2017. Model Rrencana Pemeliharaan Jaringan Listrik di Kabupaten Barito Kuala. Jurnal Teknologi Berkelanjutan (Sustainable Technology Journal), Vol. 6 No. 2. hal. 84 - 83, ISSN: 2302-8394

Winayu, S, dkk. 2010.Buku 1 Kriteria Desain Enjiniring Konstruksi Jaringan Distribusi Tenaga Listrik, PT. PLN 